\title{
A quick-assessment procedure to evaluate the degree of conservation of rockfall drapery meshes
}

\author{
M. Marchelli, V. De Biagi, D. Peila \\ Politecnico di Torino, Turin, Italy \\ maddalena.marchelli@polito.it, https://orcid.org/0000-0002-9919-2916 \\ valerio.debiagi@polito.it, http://orcid.org/0000-0003-1866-9362 \\ daniele.peila@polito.it, bttps://orcid.org/0000-0002-1771-8874
}

\begin{abstract}
Drapery meshes are protection devices installed on a cliff for mitigating rockfall hazard. They can prevent the detachment of rock fragments and control the dynamics of the falling blocks. During their design working life, drapery meshes are subjected to ageing phenomena, corrosion and impact, which can invalidate the purposes of the protection devices. A novel procedure based on a multi-hierarchical assessment of the damages is proposed. The approach is tailored for two technologies well diffused in the Alps. The main components of the system are identified and the effects of each potential damage on the overall behaviour are taken into account through risk analysis approached. A site campaign serving to test the procedure is described. The proposed approach can be modified to consider other drapery mesh installation types.
\end{abstract}

KEYWORDS. Rockfall; Drapery mesh; Quick assessment; Ageing effects

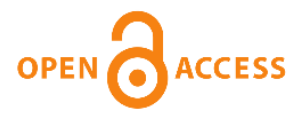

Citation: Marchelli, M., De Biagi, V., Peila, D., A quick-assessment procedure to evaluate the degree of conservation of rockfall drapery meshes, Frattura ed Integrità Strutturale, 47 (2019) 437-450.

Received: 24.09 .2018

Accepted: 11.12 .2018

Published: 01.01.2019

Copyright: (C) 2018 This is an open access article under the terms of the CC-BY 4.0, which permits unrestricted use, distribution, and reproduction in any medium, provided the original author and source are credited.

\section{INTRODUCTION}

$\mathrm{R}$ ockfall represents one of the most hazardous landslide phenomena that can cause fatalities to people and damages to structures and infrastructures [1-3]. Protection structures are installed for reducing rockfall risk in inhabited areas. These can be classified into active (if rock block instability is prevented) and passive (if the blocks are intercepted and stopped before reaching the targets). Drapery meshes are protection structures that can be classified either passive or both active and passive simultaneously [4]. They generally consist of steel wire mesh panels, suspended from upslope anchors [5], capable to control the movement of rock fragments (acting as an active protection), to withstand the punching force of falling rocks, driving the detached blocks at the foot of the slope in a controlled manner (acting as a passive protection). To achieve such goals, the mesh should be kept as close as possible to the slope and be secured both at the top and the bottom of the slope. This is one of the most adopted solutions in case of cliffs close to transportation route or to inhabited areas [6]. Other types of passive protection systems comprise embankment and ditches, rockfall protection galleries and flexible protections systems, such as rockfall barriers [3].

Various technical solutions exist [4]. They generally consist of a suspended mesh, with additional horizontal and vertical ropes. In addition, the drapes can be combined also with face bolts or other kind of anchors, which directly act on the stability of the block, connected each other and to the nets through diagonal ropes. This system prevents rockfall and 
controls its dynamics containing the small falling fragments into delimited sectors of the mesh. It can be adopted in various situations such as when the degree of fragmentation is high, or when localised unstable blocks are highlighted, it represents a powerful alternative solution to rockfall barriers/fences when the release area is small and the expected rockfall bounce height or kinetic energy are excessive.

The recent studies on such rockfall mitigation structures mainly focus on the design methods [7-9] and the numerical modelling [10-14]. Experimental studies have been performed on real scale installations [4] or on single components [11, 15]. Recently, Gratchev and colleagues analysed the friction mechanisms that form between the net and the face, which can be identified as the main contribution to the functioning of the rockfall protection [16]. The effects of snow and ice on the mesh are significant for the design of the anchors as noted by Shu et al. [15].

To our knowledge, the efficiency over the time of drapery systems has not been object of study, yet. The majority of the studies focused the attention on the time-dependent effects on a single component of the system: the anchors [17-19]. As any structure, drapery nets are multicomponent protection devices that can be compromised during time. Ageing, corrosion, interactions with blocks, vegetation, wild animals, or people can affect the integrity and the structural capabilities of the systems. Lacerations or bowings in the net, corrosion, or detachment of the anchors are the most common damages that can occur. In this perspective, periodic surveys are required to investigate performance level over time of such systems. Although surveying such systems is often critical, the evaluation of the degree of damage of such structures is, in fact, fundamental for defining a priority scale of maintenance interventions, to be related with rockfall risk, i.e. with rockfall probability of occurrence and exposure in a given area. Thus, an assessment of the efficiency of drapery mesh is required. Due to the extension and variety of drapery nets systems, e.g. in the Alps, the protocol needs to be as general as possible, avoiding time-consuming and expensive ad-hoc survey campaigns, or an ongoing monitoring and surveillance system.

With this perspective, the present work aims to introduce an encoded expeditious procedure to evaluate the degree of degradation of drapery mesh systems, assessing their state of conservation. This method represents a compelling solution for both authorities and designers in risk evaluation and management strategies. The presented work is based on a multicriteria analysis, involving an encoded screening survey.

\section{EFFICIENCY OF AGED DRAPERY NETS}

$\mathrm{D}$ espite their worldwide use, no universally recognised guidelines or technical standards exist for the design of drapery systems [4]. Their mechanisms of passive or combined passive/active rockfall protection have been under debate for a long time [8]. Furthermore, the uncertainties of the loading conditions (snow, debris, etc.) to consider in the design increase the difficulty to encode a standard design procedure. As a consequence, empirical and simplified design approaches have been adopted, based on the geotechnical specialists' experience, incurring sometimes in under-sized elements [20]. The design procedure needs to account for the influence of the mesh weight, the friction interface between the slope and the mesh and the possible accumulation of debris [21]. The first drapery mesh installations date back to the Fifties [12]. At present, the "Design Guidelines for wire mesh/cable net slope protection" [20] issued by the Washington State Department of Transportation are the only rules for the complete design of a simple drapery system. In 2012, the Italian Standardisation Committee released the UNI 11437 standard [22], which describes the punching test procedures on meshes for slope coverage. With particular reference to the tests on the net ASTM A975 standard [23] must be considered. In the following, the essential components constituting a drapery mesh system are listed in the attempt to create a list as general as possible for the large variety of installations. Both simple and reinforced types are investigated. The possible damages on each part were investigated, considering the effects of aging, corrosion, weathering, impacts with blocks, interactions with debris, vegetation, animals and even people. At the end, the influence of degrade on aged components on the global efficiency of the system is discussed.

The analyses reported in the following refer to the study cases found in the previously mentioned bibliography. A widespread survey campaign was performed in the Northwestern Italian Alps, where a large variety of rockfall protections are installed. As a consequence, the proposed method is tailored to the common European protection systems.

\section{Main elements of a drapery net}

Generally speaking, drapery systems can be classified into two main typologies: simple drapery or reinforced wire mesh drapery [4]. Simple wire mesh drapery systems (Fig. 1.a) are essentially made of metallic nets (wire or ropes) fixed at the top with anchors. A top rope serves for ensuring the stability of the mesh. Usually, additional fixing points (and a rope) are present at the bottom of the net. The nets are left unanchored along the slope. They control the dynamics of the falling of debris and rock elements along the slope, preventing their bouncing. Sometimes vertical and/or horizontal metallic ropes 
are present, increasing the adhesion of the net to the slope, but without other specific structural aim. The mesh has to resist tangential and normal forces induced by falling blocks that can tear or puncture the mesh. Reinforced drapery meshes (Fig. 1.b) are essentially made in the same way as the simple meshes. Besides, additional metallic ropes fixed to the cliff through a regular pattern of bolts enforce the adhesion of the net to the rock face. This system allows the small falling blocks to be collected into delimited sectors of the mesh and increases the stability of the fragmented face through the bolts, i.e. exerting an active role.
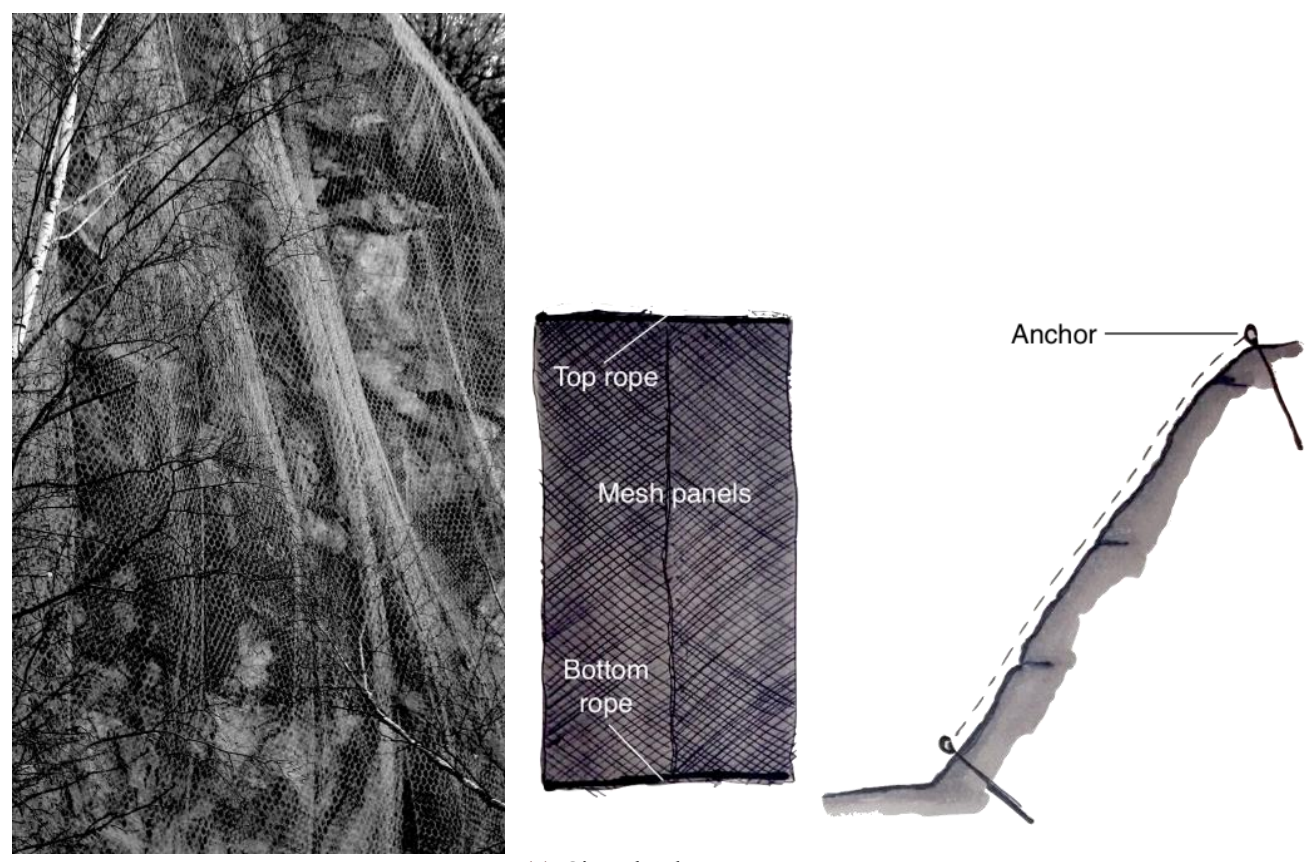

(a) Simple drapery net
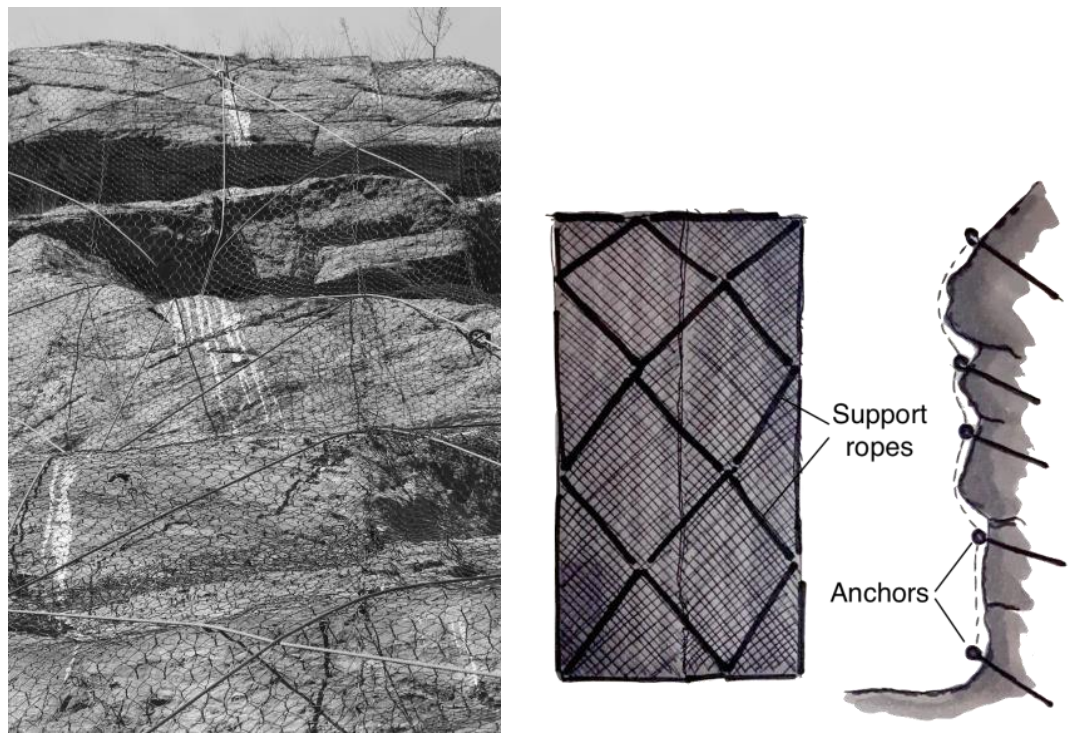

(b) Reinforced drapery net

Figure 1: Views and sketches of (a) the simple drapery net and (b) the reinforced drapery net installations. Note that the reinforced drapery net follows the shape of the cliff face.

The performance of the previously described systems depends on the adopted solutions for the mesh, the ropes, and the anchors. Nets are made of steel wire meshes, which can be single-twisted rhomboidal or double twisted hexagonal. Other solutions consist in cable net panels made of metallic cables, connected with clips or knots, or ring net panels, laced together with steel cables or other devices. Usually, cable net is combined with wire mesh to intercept smaller blocks. Panels are 
connected each other with clips or knots, or sewed up with a steel wire or cable passing through the whole panels edges (Fig. 2). Supporting elements, i.e. the top and the bottom ropes, and the reinforcing ropes, are made of galvanised steel. The anchors are usually grouted bars or injected cables. The connection between the anchor and the ropes can be various according to anchor type. At the ends of grouted bars, eye-bolt solution (with or without plate), bolted anchorage plates with anchor nuts, or a grouted U-bolt are directly connected with the ropes, passing through the hoop. In the injected cable case, the rope directly passes through a rope loop, or it is connected to it by means of a shackle. Nevertheless, a large variety of technologies for fixing can be found (Fig. 3). The metallic ropes are held in tension through rope clips. A large variety of technologies for fixing and connecting the various components of the system can be found. With the aim to encompass the largest number of drapery types, the elements to consider in the performance evaluation are listed in Tab. 1 grouping together a rope with its anchors. It must be noticed that in simple drapery systems the intermediate ropes do not play a structural support function. In this sense, the term "intermediate ropes" was adopted. On the contrary, "support ropes" was chosen for the reinforced systems. "Top" and "bottom" ropes are the shortened version of top and bottom boundary ropes, respectively.

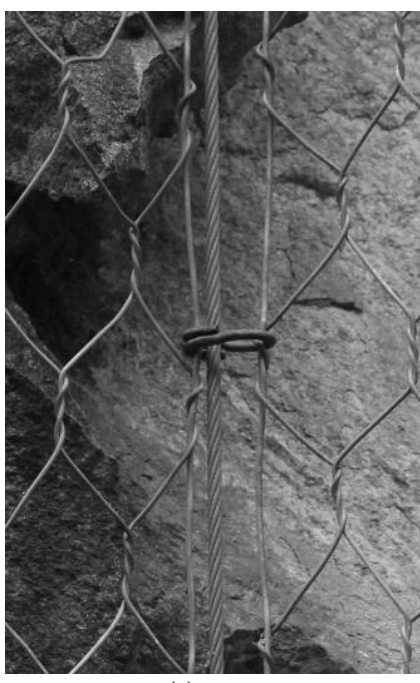

(a)

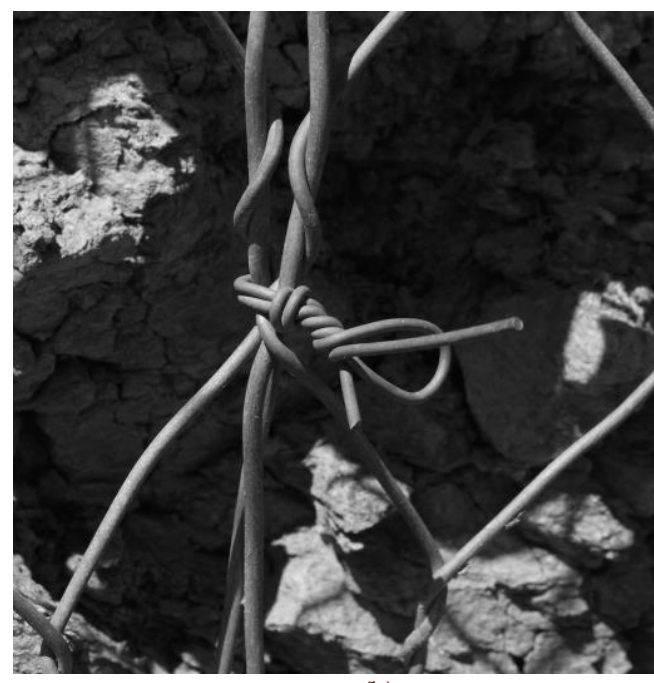

(b)

Figure 2: Different connections between the panels: (a) a vertical rope with clips, (b) knots (close view).

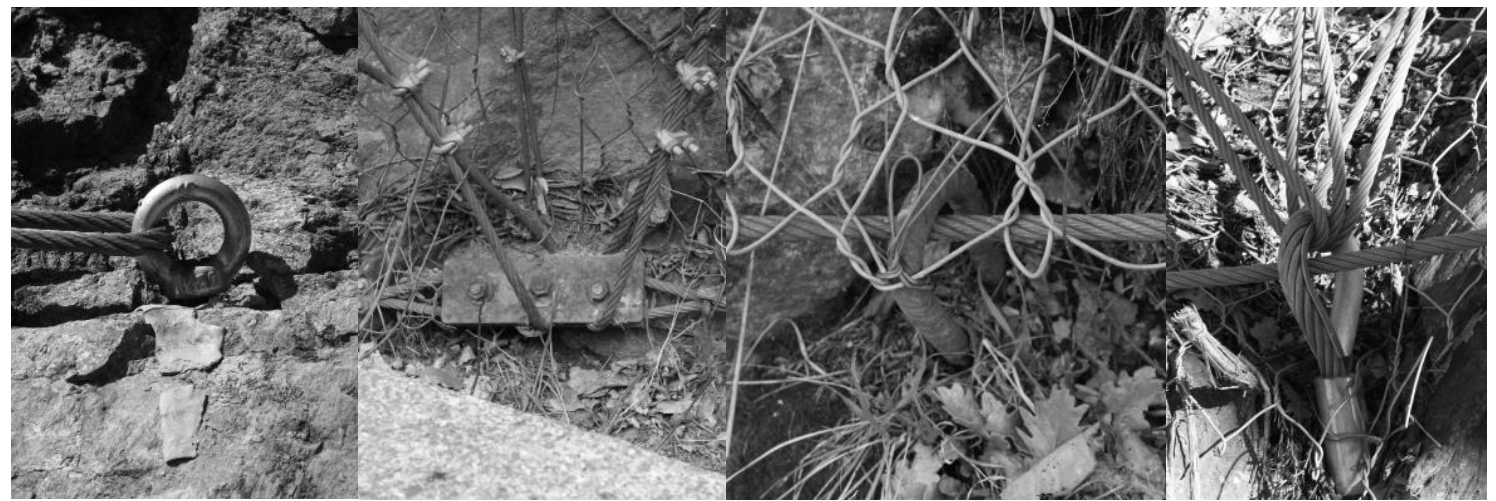

(a) (c) (d)

Figure 3: Different anchors types and connection with the ropes and the mesh: (a) a grouted bar with a screwed steel hoop, (b) an injected cable, (c) a grouted bar with a plate, (d) an anchorage plate.

\section{Damages on the elements}

All the possible critical scenarios or damages occurring on the main components of the drapery system, identified in Tab. 1, are evaluated. Tab. 2 reports a list of potential damages, i.e. the damages that can occur on each component if subjected to certain stress/environmental conditions. In the third column of Tab. 2, the observed damages are reported. These are a 
complete list of already occurred damages that can preclude the correct functioning of the drapery system, as detailed in the following.

\section{Main components}

Mesh

Top rope: rope, anchors, anchor-rope connections

Bottom rope: rope, anchors, anchor-rope connections

Intermediate ropes: ropes, anchors, anchor-rope connections (only simple drapery system)

Support ropes: ropes, anchors, anchor-rope connections (only reinforced drapery system)

Connection between mesh panels

Mesh-top rope connection

Mesh-bottom rope connection

Mesh-intermediate ropes connection (only simple drapery system)

Table 1: Main components of a drapery mesh system.

\section{Effects of the local damages on the global efficiency}

The local damages identified in the previous section affect the efficiency of the entire drapery system in different ways, depending both on the damaged element and on the type of damage. The elements identified in Tab. 1 play different roles in the stability and functionality of the entire system. Their damage, or absence, affects and compromises the global efficiency in different ways. As a consequence, identifying a hierarchy across the components and understanding the damage propagation and the failure processes is the key issue in the efficiency evaluation procedure.

In order to explain the double hierarchy between the components and system efficiency and between damages and system efficiency should be considered. The core of the protection system is represented by the mesh that actively acts on the statics of the potentially falling blocks and on their dynamics. All system components aimed at sustaining the mesh and keeping it in the right position are fundamental for the correct functioning of the system, and their absence (due to ageing) implies that the protection system is inefficient. These are the top rope, the connection between the wire mesh panels, and the connection between the wire mesh and the top rope for the simple drapery system. In addition, for reinforced drapery systems, the support ropes are added to the list of fundamental elements. Note that the term "ropes" refers to the overall components, including the anchorages.

Trying to find the double hierarchy levels between damages and system efficiency, the mesh is used as an example. Its integrity and adherence to the cliff are essential for an efficient protection. In case of lacerations of the mesh, the falling blocks can exit the protection structure. It might happen that the laceration is the result of a previous rock detachment event, i.e. a case in which the protection of the system did not work properly. In addition, the damages can be due to an overload or an undesired (or unexpected) type of loading. A potential damage situation (such as corrosion) can reduce the mechanical properties of the mesh, leading to a similar effect. Anyway, the removal of the corrosion protection decreases the efficiency of the system less than a laceration. As an example, other sorts of interference, such as the presence of vegetation in the drapery system, can presuppose an unexpected functioning of the installation, as described in Tab. 2.

It emerges that the several types of damages on the single elements have different degree of importance for computing the efficiency of the global system. With reference to the fixing to the cliff face, the lack of an anchor increases the failure probability of the system more than the corrosion of the same anchoring element. From a general point of view, it can be inferred that the lack of an element affects the efficiency of the system more than its corrosion, deformation, or interaction with vegetation. As a consequence, for example, during the survey operations, the assessment of the presence and the inspection of the top has to be as much accurate as possible, and the eventual presence of vegetation can prevent a careful survey.

\section{METHODOLOGY}

$\mathrm{T}$ 1 he purpose of the proposed approach is the evaluation of the residual efficiency of the investigated drapery net system types when no quantitative data from monitoring is available. The proposed method intends to be an alternative solution to a continuous monitoring, i.e. it is a tool for assessing how ageing affects the protection system. 
Thus, it is hypothesised that at the beginning of its working life, the drapery system has its maximum efficiency. The tool has not been conceived for analysing if there are design or construction errors in the protection structures. Similarly, nothing is said about the quality of the project and its effectiveness.

\begin{tabular}{ll} 
Component & \multicolumn{1}{c}{ Potential damages } \\
Mesh & The accumulation of debris at the bottom, or in the intermediate \\
parts, can cause excessive stresses in the mesh leading to the yielding \\
of the wire and the rupture of the component. Large blocks can cause \\
the punching leading to the laceration of the mesh. The growing \\
vegetation (trees) creates an additional anchor, which might be \\
unsuitable for the protection structure and be the cause of additional \\
failures. Brushes can cause water stagnation with consequent \\
corrosion. Flowing water can be the cause of corrosion. Moisture \\
supports the growing of fungi that can change the chemical \\
environment. Salty air and other environmental conditions can \\
promote corrosion
\end{tabular}

Ropes \& anchors Rust reduces the resisting cross-section area of the components. Rust damages the head of the anchor and the plate. Water or moisture can corrode the elements, damaging the grouting, and causing the deterioration the bond between bolts and grouting with the consequent unthreading. Excessive forces due to debris accumulation can cause unthreading of the anchors

Connections Rust reduces the cross-section area of the connection
between mesh
panels

\section{Observed damages}

Lacerations, bowing, excessive

deformations, rust, lack of corrosion protection
Fraying or/and rusting of the ropes, unconnected ropes, rust on the rope clips, unthreading of anchors, rust on the anchors, rust on the head of the anchors, rust on the plates, lack of the connector, lack of the rope clips

Reduced number of connection devices (e.g. clips or knots), rust on the connector, lack of any sort of connection

Mesh-rope If the rope is sewed up in the mesh, local damages on the mesh can connections make the connection inefficient

Table 2: Potential and observed damages on the main components of the system.

The main idea of the approach is to consider the mutual dependencies between the main components and global failure, and local damages and main component, to quantify the residual capacity. The double hierarchy evaluation process described was automated and encoded. In this perspective, assuming a periodic investigation on the efficiency of the structure, a check list of the issues to consider and assess was provided. Depending on the drapery system type, two different lists in which each entry represents a possible local damage or critical situation for an element of the drapery system were proposed. The two left-hand side columns of Tab. 3 and 4 report the considered issues for each component of simple and reinforced drapery net systems, respectively.

From a technical point of view, it is expected that an expert (say an engineer or a geologist) is called for a periodic survey of the structure, assessing the damage, deterioration, or even to mark the fact that the component is missing. Three increasing damage levels were introduced, as described in Tab. 5. Due to the inherent subjectivity of the approach, which is operator-based, the choice of three levels seems to be a profitable solution. Fig. 4 shows examples of damage states according to the authors. 
To consider the different influence of these issues on the maintenance of the system efficiency, different weights were associated to each point of the check list. Based on the outcomes of past studies reported in the literature, the highly qualified experience of the authors, and in-situ observations, three importance classes were defined: $\mathrm{C} 1$ when the influence of the issue to the overall efficiency is negligible, $\mathrm{C} 2$ when the issue might influence the protection system, and C3 when the issue is critical and dramatically reduces the efficiency of the protection system. The right-hand side columns of Tab. 3 and 4 report the importance class of each point of the check list.

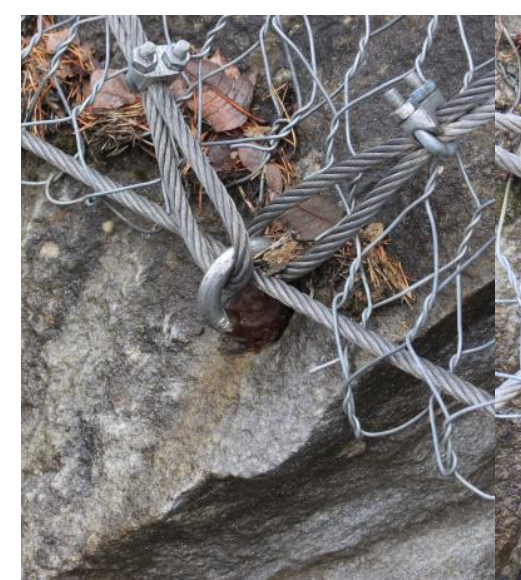

(a)

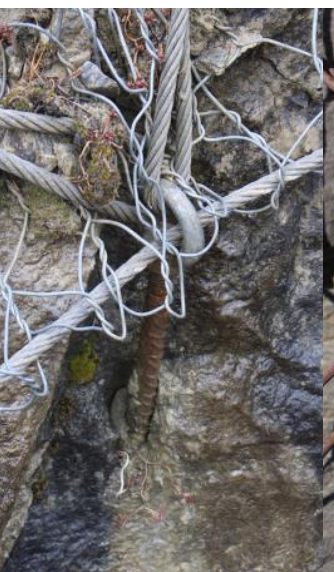

(b)

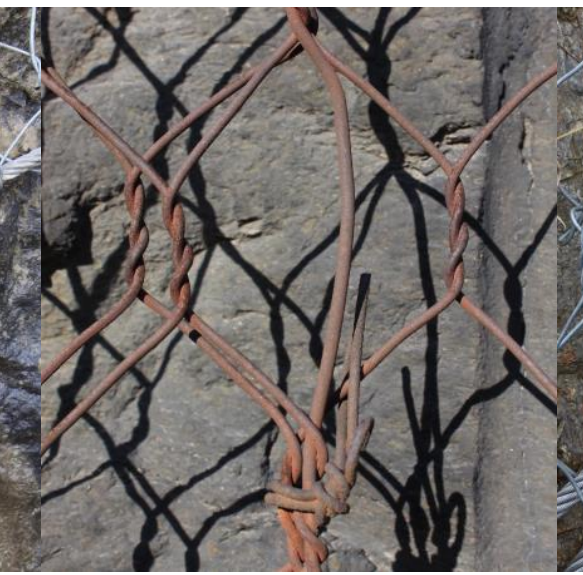

(c)

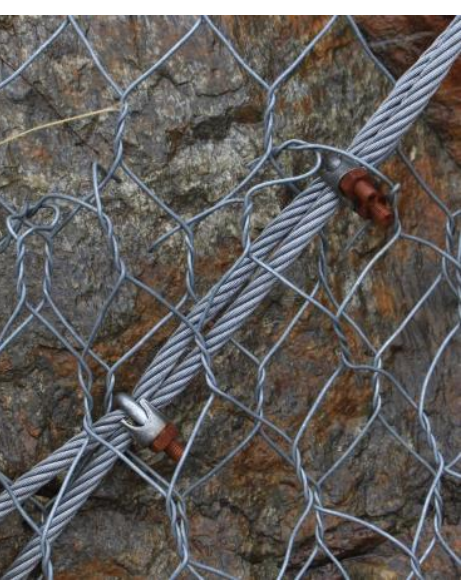

(d)

Figure 4: Examples of different damage levels attributed to various components. Different anchors types and connection with the ropes and the mesh: (a) Damage on the plate and/or on the head of the anchors - D1, (b) Unthreading of the anchors - D2, (c) Presence of corrosion and/or removal of the corrosion protections of the mesh - D2, (d) Presence of corroded zones and/or significant damage of the rope $-\mathrm{D} 1$.

\section{Definition of the maintenance level of the system}

The level of damage for each element and the class of importance were matched to evaluate the efficiency of the whole drapery mesh system. The method mimics two techniques adopted in risk assessment: weighted sum and matrix approaches. The former represents one of the most common empirical method to evaluate the hazard associated to a natural disaster. It consists in the assignment of a global score, increasing for higher hazard, obtained as a function of the presence of some predisposing factors, weighted by the importance of each. At each factor, a score is assigned and the global score derives from the weighted sum of the single scores divided by the weighted maximum. The weighted process partially limits the inherent subjectivity of the method [24, 25]. Matrix evaluation techniques are a widely employed and are profitable methods for evaluating the risk level. These methods are based on the subdivision in categories for both the probability of occurrence of an event (usually the rows of the risk matrix) and the severity of the consequences (the columns). Each cell of the matrix identifies a risk level $[24,26]$ These two methods were tailored, revised and partially combined to define the efficiency of the whole drapery mesh. Tab. 6 details the score assigned to each damage level - importance factor. The global score of the drapery mesh is the summation of each single score. The score increases as much as the residual efficiency reduces. The greater the number of elements that exhibit criticality is, the higher the global score. The weighted maximum scores range from 0 to 113 for simple drapery nets, and from 0 to 109 for reinforced drapery nets, provided that all elements are present, while the global score ranges from $0 \%$ to $100 \%$. If one (or more) are absent, all the local/potential damages linked to these are not considered in the weighted global maximum, i.e. if a rope is missing, all damages related to anchor and connection are not considered.

As previously detailed, it emerges that either the deterioration of several minor components or the damage of a unique principal part of a drapery system can compromise the whole system efficiency. In addition, the system can be ineffective even though a single component is in a highly damaged situation. This occurs if the component is fundamental and the expected consequence is marked as C3. In this particular case, for example, the global score is low, but a sudden maintenance work is needed. As a consequence, another additional qualitative indicator is associated to the system relating to the state of conservation of the system, indicating if a sudden repair is needed to restore the system to its initial condition. A risk-matrix was defined, as shown in Tab. 6. Three maintenance levels were introduced, depending on both the level of damage and the class of importance of the component: A0 if a long-term maintenance plan is needed, A1 if a short/medium-term maintenance plan is needed, and A2 if urgent maintenance is needed. The maintenance level of the whole system is the worst maintenance level obtained by each component. In this way, if almost one part has maintenance lever A2, the drapery 
mesh system requires a sudden maintenance, while A1 identifies a partial loss of functionality that can be recovered in larger times. In addition, the number of damaged components directly relates to the extent of the required intervention works.

\begin{tabular}{|c|c|c|}
\hline Component & Local or potential damage & $\mathrm{Col}$ \\
\hline Wire mesh & $\begin{array}{l}\text { Significant amount of debris in the foot of the slope } \\
\text { Presence of debris in the mesh } \\
\text { Presence of weeds, bushes or trees interacting with the mesh } \\
\text { Lacerations in the mesh } \\
\text { Deformations or bowing of the mesh } \\
\text { Presence of corrosion and/or removal of the corrosion protections of the mesh }\end{array}$ & $\begin{array}{l}\text { C3 } \\
\text { C2 } \\
\text { C2 } \\
\text { C3 } \\
\text { C3 } \\
\text { C1 }\end{array}$ \\
\hline Top rope & $\begin{array}{l}\text { Absence of the rope } \\
\text { Presence of corroded zones and/or significant damage of the rope } \\
\text { Absence of the anchors } \\
\text { Missing rope-anchors connection elements } \\
\text { Corrosion of the anchors } \\
\text { Damage on the plate and/or on the head of the anchors } \\
\text { Unthreading of the anchors }\end{array}$ & $\begin{array}{l}\text { C3 } \\
\text { C3 } \\
\text { C3 } \\
\text { C3 } \\
\text { C1 } \\
\text { C2 } \\
\text { C3 }\end{array}$ \\
\hline Bottom rope & $\begin{array}{l}\text { Presence of corroded zones and/or significant damage of the rope } \\
\text { Partially visible rope as hidden by debris/vegetation } \\
\text { Absence of the rope } \\
\text { Non-visible anchor } \\
\text { Absence of the anchors } \\
\text { Missing rope-anchors connection elements } \\
\text { Corrosion of the anchors } \\
\text { Damage on the plate and/or on the head of the anchors } \\
\text { Unthreading of the anchors }\end{array}$ & $\begin{array}{l}\mathrm{C} 2 \\
\mathrm{C} 1 \\
\mathrm{C} 2 \\
\mathrm{C} 1 \\
\mathrm{C} 2 \\
\mathrm{C} 2 \\
\mathrm{C} 1 \\
\mathrm{C} 2 \\
\mathrm{C} 2\end{array}$ \\
\hline $\begin{array}{l}\text { Intermediate } \\
\text { ropes (if present) }\end{array}$ & $\begin{array}{l}\text { Presence of corroded zones and/or significant damage of the rope } \\
\text { Partially visible rope as hidden by debris/vegetation } \\
\text { Absence of the rope } \\
\text { Non-visible anchor } \\
\text { Absence of the anchors } \\
\text { Missing rope-anchors connection elements } \\
\text { Corrosion of the anchors } \\
\text { Damage on the plate and/or on the head of the anchors } \\
\text { Unthreading of the anchors }\end{array}$ & $\begin{array}{l}\text { C1 } \\
\text { C1 } \\
\text { C1 } \\
\text { C1 } \\
\text { C1 } \\
\text { C1 } \\
\text { C1 } \\
\text { C1 } \\
\text { C1 }\end{array}$ \\
\hline $\begin{array}{l}\text { Connection } \\
\text { between mesh } \\
\text { panels }\end{array}$ & $\begin{array}{l}\text { Missing elements } \\
\text { Presence of corroded zones and/or damages of the connection elements }\end{array}$ & C3 \\
\hline $\begin{array}{l}\text { Mesh-top rope } \\
\text { connection }\end{array}$ & $\begin{array}{l}\text { Missing elements } \\
\text { Presence of corroded zones and/or damages of the connection elements }\end{array}$ & C3 \\
\hline $\begin{array}{l}\text { Mesh-bottom } \\
\text { rope connection }\end{array}$ & $\begin{array}{l}\text { Missing elements } \\
\text { Presence of corroded zones and/or damages of the connection elements }\end{array}$ & $\begin{array}{l}\mathrm{C} 2 \\
\mathrm{C} 1\end{array}$ \\
\hline $\begin{array}{l}\text { Mesh- } \\
\text { intermediate } \\
\text { ropes connection }\end{array}$ & $\begin{array}{l}\text { Missing elements } \\
\text { Presence of corroded zones and/or damages of the connection elements }\end{array}$ & $\begin{array}{l}\mathrm{C} 2 \\
\mathrm{C} 1\end{array}$ \\
\hline
\end{tabular}

Table 3: Classes of importances (CoI) for the assessment of the residual efficiency for all the considered components in simple drapery net systems (maximum equal to 113). 


\begin{tabular}{|c|c|c|}
\hline Component & Local or potential damage & $\mathrm{CoI}$ \\
\hline Wire mesh & $\begin{array}{l}\text { Significant amount of debris in a portion defined with } 4 \text { anchors } \\
\text { Presence of debris in the mesh } \\
\text { Presence of weeds, bushes or trees interacting with the mesh } \\
\text { Lacerations in the mesh } \\
\text { Deformations or bowing of the mesh } \\
\text { Presence of corrosion and/or removal of the corrosion protections of the mesh }\end{array}$ & $\begin{array}{l}\text { C3 } \\
\text { C1 } \\
\text { C1 } \\
\text { C3 } \\
\text { C3 } \\
\text { C1 }\end{array}$ \\
\hline Top rope & $\begin{array}{l}\text { Absence of the rope } \\
\text { Presence of corroded zones and/or significant damage of the rope } \\
\text { Absence of the anchors } \\
\text { Missing rope-anchors connection elements } \\
\text { Corrosion of the anchors } \\
\text { Damage on the plate and/or on the head of the anchors } \\
\text { Unthreading of the anchors }\end{array}$ & $\begin{array}{l}\text { C2 } \\
\text { C3 } \\
\text { C3 } \\
\text { C3 } \\
\text { C1 } \\
\text { C2 } \\
\text { C3 }\end{array}$ \\
\hline Bottom rope & $\begin{array}{l}\text { Absence of the rope } \\
\text { Presence of corroded zones and/or significant damage of the rope } \\
\text { Partially visible rope as hidden by debris/vegetation } \\
\text { Non-visible anchor } \\
\text { Absence of the anchors } \\
\text { Missing rope-anchors connection elements } \\
\text { Corrosion of the anchors } \\
\text { Damage on the plate and/or on the head of the anchors } \\
\text { Unthreading of the anchors }\end{array}$ & $\begin{array}{l}\text { C2 } \\
\text { C2 } \\
\text { C1 } \\
\text { C1 } \\
\text { C1 } \\
\text { C1 } \\
\text { C1 } \\
\text { C1 }\end{array}$ \\
\hline Support ropes & $\begin{array}{l}\text { Presence of corroded zones and/or significant damage of the rope } \\
\text { Absence of the rope } \\
\text { Absence of the anchors } \\
\text { Missing rope-anchors connection elements } \\
\text { Corrosion of the anchors } \\
\text { Damage on the plate and/or on the head of the anchors } \\
\text { Unthreading of the anchors }\end{array}$ & $\begin{array}{l}\text { C1 } \\
\text { C3 } \\
\text { C3 } \\
\text { C3 } \\
\text { C1 } \\
\text { C2 } \\
\text { C3 }\end{array}$ \\
\hline $\begin{array}{l}\text { Connection } \\
\text { between mesh } \\
\text { panels }\end{array}$ & $\begin{array}{l}\text { Missing elements } \\
\text { Presence of corroded zones and/or damages of the connection elements }\end{array}$ & $\begin{array}{l}\mathrm{C} 3 \\
\mathrm{C} 2\end{array}$ \\
\hline $\begin{array}{l}\text { Mesh-top rope } \\
\text { connection }\end{array}$ & $\begin{array}{l}\text { Missing elements } \\
\text { Presence of corroded zones and/or damages of the connection elements }\end{array}$ & $\begin{array}{l}\text { C3 } \\
\text { C2 }\end{array}$ \\
\hline $\begin{array}{l}\text { Mesh-bottom } \\
\text { rope connection }\end{array}$ & $\begin{array}{l}\text { Missing elements } \\
\text { Presence of corroded zones and/or damages of the connection elements }\end{array}$ & $\begin{array}{l}\mathrm{C} 2 \\
\mathrm{C} 1\end{array}$ \\
\hline
\end{tabular}

Table 4: Classes of importances (CoI) for the assessment of the residual efficiency for all the considered components in reinforced drapery net systems (maximum equal to 109).

\begin{tabular}{|c|c|c|}
\hline Damage level & Mesh \& Ropes & Anchors \& Connectsions \\
\hline D0 & $\begin{array}{l}\text { The considered damage is absent or } \\
\text { limited to a very reduced portion (up to } \\
25 \% \text { ) }\end{array}$ & $\begin{array}{l}\text { None of the parts is damaged. The } \\
\text { element is present }\end{array}$ \\
\hline D1 & $\begin{array}{l}\text { The considered damage is diffused } \\
\text { (from } 25 \% \text { to } 75 \% \text { ) }\end{array}$ & $\begin{array}{l}\text { A slight or intermediate of damage is } \\
\text { present, at least in one anchor or } \\
\text { connection }\end{array}$ \\
\hline $\mathrm{D} 2$ & $\begin{array}{l}\text { A large part of the component is affected } \\
\text { by the considered damage (from } 75 \% \text { ) }\end{array}$ & $\begin{array}{l}\text { At least one part is damaged. The } \\
\text { element is absent. }\end{array}$ \\
\hline
\end{tabular}

Table 5: Damage levels on the components of a drapery system. 


\begin{tabular}{cccc}
\hline & C1 & C2 & C3 \\
D0 & $0(\mathrm{~A} 0)$ & $0(\mathrm{~A} 0)$ & $0(\mathrm{~A} 0)$ \\
D1 & $1(\mathrm{~A} 0)$ & $2(\mathrm{~A} 0)$ & $3(\mathrm{~A} 1)$ \\
D2 & $2(\mathrm{~A} 0)$ & $3(\mathrm{~A} 1)$ & $5(\mathrm{~A} 2)$ \\
\hline
\end{tabular}

Table 6: Table of the scores and the maintenance level (in square brackets) attributed to each entry of the check lists reported in Tabs. 3 and 4, depending on the level of damage and the class of importance.

\section{STUDY CASES}

he residual efficiency assessment procedure herein proposed was tested in various sites located in the Northwestern Italian Alps. The campaign serves both for verifying the influence of the single damages on the overall functioning of the rockfall mitigation structures and for testing the capabilities of a matrix approach, evaluating if the proposed procedure is able to minimise the subjectivity, which is intrinsic in such man-made survey operations. The investigated structures are directly placed above local and national roads. Their selection was based on the possibility to reach the top of the drapery net. The sites are located at an altitude ranging from 300 to $1100 \mathrm{~m}$ a.s.l. The slope angle of the cliffs onto which the surveyed drapery nets are installed is variable: gentle slopes as well as overhanging cliffs were examined. A large heterogeneity in the characteristics of the protective structures was observed. In detail, the size of the nets is between 20 to $500 \mathrm{~m}$ in length and 5 and $30 \mathrm{~m}$ in height. As expected, various net types and damage levels were observed. In the following, the relevant aspects of the survey campaign are reported. Three study cases are illustrated (Tab. 7 details the scores attributed to each component).

Fig. 5.a shows a simple drapery net system (Case A) installed in a debris slope, in which a few anchors of the top rope are unthreaded. The assigned damage level at "Top rope - Unthreading of the anchors" entry of Tab. 3 is D2 since the element is missing, i.e. at least one anchor is unthreaded. Considering the importance class of this damage, i.e. C3, the maintenance level raises up to A2, requiring urgent intervention works. This outcome of the procedure is confirmed by the fact that the system is no more capable to drive the debris at the foot of the slope in a controlled way. The spacing between two fixing points is large and the top rope is slack engendering an unsuited deformation of the wire mesh, which loses its adhesion to the slope. In this particular case, both signs of corrosion on top and bottom ropes and a significant amount of debris accumulated in the foot of the slope were observed.

Fig. 5.b shows a reinforced drapery system (Case B) installed on a vertical gneiss cliff. The visual inspection reports a wellpreserved anchoring system. The local damages affect the support ropes, with a small degree of corrosion, the connection between the wire mesh panels. The wire mesh is slightly corroded, with vegetation interacting with it. The global maintenance level is A1, i.e. medium plan intervention, while the global score is quite high (32). The observed situation is well represented by the outcomes of the procedure, since the system preserve a certain degree of functionality.

Fig. 5.c shows a reinforced drapery system (Case C) located in a debris slope. The visual inspection reports that no corrosion problems emerge, with a global well-preserved situation. The presence of vegetation interacting with the mesh represents the only critical situation. With the adoption of the proposed method, the global maintenance level is A1, i.e. long term intervention works, and the global score is low (2). This result is in complete agreement with what observed.

It is worth noting that Case A and Case B have similar overall score, meaning that the overall damage level is similar, i.e. in both cases several elements are damaged. Anyway, in Case A only the damage precludes the correct functioning of the protection system, i.e. the maintenance levels are different.

As an overall comment, the driving idea of classifying the components into main categories helps in dealing with the heterogeneity of techniques within the same site. For example, different mesh types (wire mesh and cable net) are sometimes combined, see Fig. 6.a, or different anchoring devices are used. More frequently, the two investigated different drapery net systems occur in sequence, i.e. a simple and a reinforced drapery nets, as shown in Fig. 6.b. In this case, since the check list is system-dependent, two different analyses must be considered, as the influence of the local damages on the global efficiency varies. 


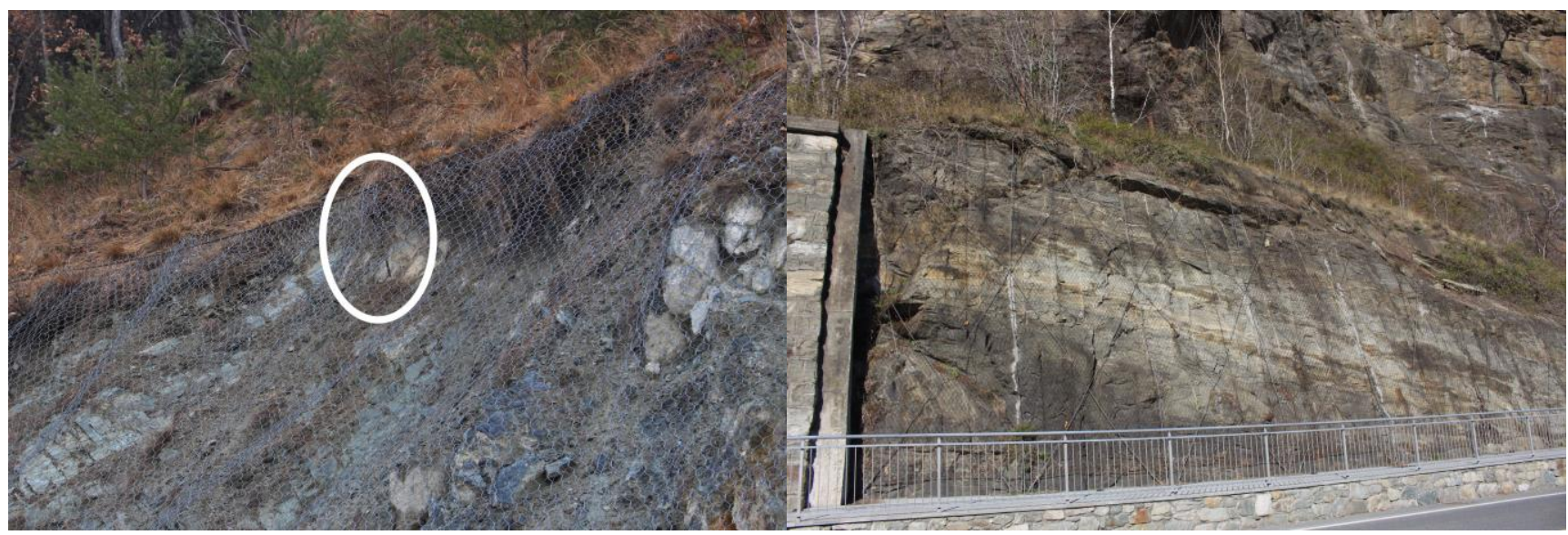

(a) Case A

(b) Case B

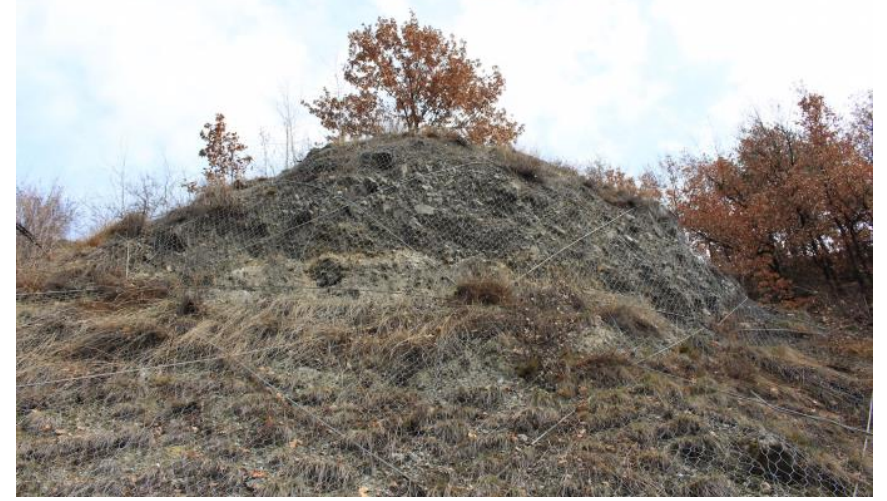

(c) Case C

Figure 5: Photos of three installations observed during the site campaign: Case A is a simple drapery mesh system, the unthreaded anchor is marked with the white circle. Case $B$ and Case $C$ refer to reinforced drapery systems.

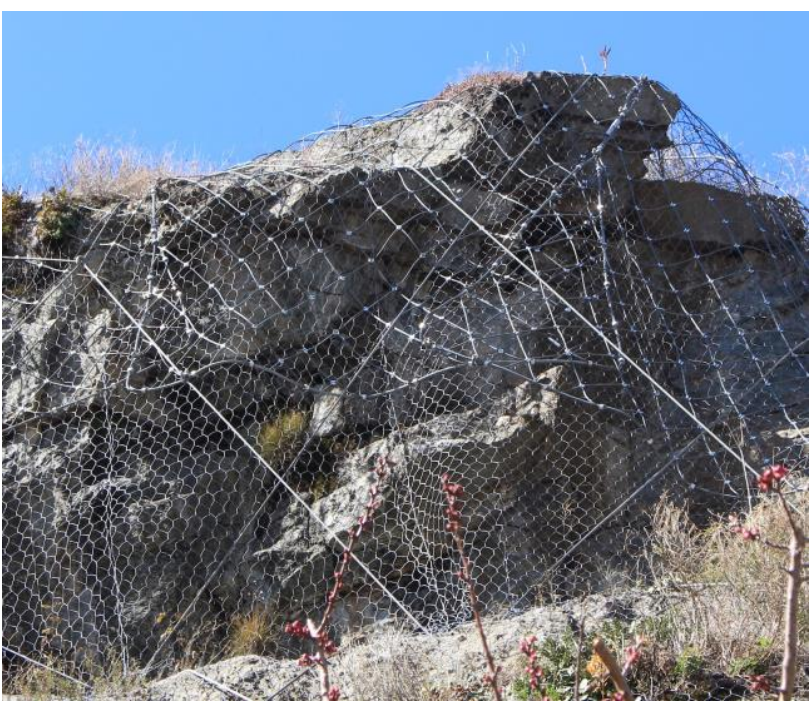

(a)

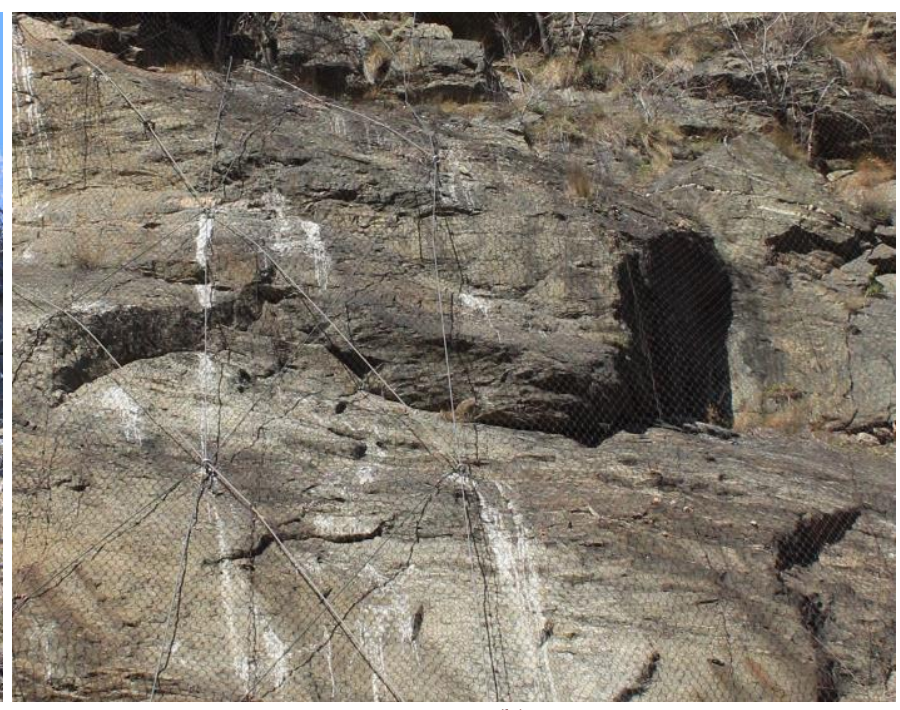

(b)

Figure 6: In (a) two mesh types are adopted; in (b) the simple and the reinforced drapery systems are adjacent in the same site. 


\begin{tabular}{cccc}
\hline Component & $\begin{array}{c}\text { Case A } \\
\text { (maximum 90) }\end{array}$ & $\begin{array}{c}\text { Case B } \\
\text { (maximum 105) }\end{array}$ & $\begin{array}{c}\text { Case C } \\
\text { (maximum 105) }\end{array}$ \\
Wire mesh & $12(\mathrm{~A} 2)$ & $11(\mathrm{~A} 1)$ & $2(\mathrm{~A} 0)$ \\
Top rope & $15(\mathrm{~A} 2)$ & $3(\mathrm{~A} 0)$ & $0(\mathrm{~A} 0)$ \\
Bottom rope & $10(\mathrm{~A} 1)$ & $4(\mathrm{~A} 0)$ & $0(\mathrm{~A} 0)$ \\
Intermediate ropes & $0^{*}(\mathrm{~A} 0)$ & & $0(\mathrm{~A} 0)$ \\
Support ropes & & $4(\mathrm{~A} 0)$ & $0(\mathrm{~A} 0)$ \\
Connection between mesh panels & $0(\mathrm{~A} 0)$ & $5(\mathrm{~A} 1)$ & $0(\mathrm{~A} 0)$ \\
Mesh-top rope connection & $0(\mathrm{~A} 0)$ & $5(\mathrm{~A} 1)$ & $0(\mathrm{~A} 0)$ \\
Mesh-bottom rope connection & $0(\mathrm{~A} 0)$ & $0(\mathrm{~A} 0)$ & $1 \%$ \\
Mesh-intermediate rope connection & $0^{*}(\mathrm{~A} 0)$ & & $30 \%$ \\
Global score & $52 \%$ & & \\
\hline
\end{tabular}

Table 7: Results of the survey campaign on the three cases commented in the text. The sum of the scores and the most severe maintenance level (in round brackets) are reported for each component. If the component is not present, a sign $*$ is added to the score.

\section{CONCLUSIONS AND FURTHER OUTLOOKS}

rapery net systems are widely employed and profitable measures to mitigate the risk of rockfall events. Nevertheless, their failure or destruction would cause serious consequences, both in term of causalities and economical damages. Due to their importance, a continuous monitoring would be profitable to evaluate the maintenance of their efficiency despite ongoing ageing and/or local damages. Unfortunately, continuous or periodic monitoring is rarely adopted, as it is high time-consuming, and thus no quantitative data are available for the planning of the maintenance works.

As a consequence, the proposed quick-assessment procedure herein reported aims at addressing the problem of estimating the efficiency of a rockfall drapery mesh system and establishing a priority list for intervention works. The presented method is based on a multi-criteria analysis, involving an encoded screening survey. The leading idea is that either the deterioration of several minor elements or the damage of a unique fundamental element of a drapery system can compromise the whole system efficiency. This entails a double hierarchy problem, since the final evaluation depends both on the damaged/deteriorated part and on the magnitude of the damage itself. The process is implemented through a list of observed items that the surveyor must check in analysing the protection structure. A damage level and a class of importance for each entry let to assign a global score and a maintenance level to the structure, indicating if urgent reparation works are needed. The lack in the prescriptions for such kind of hazard mitigation structures lead the authors in fixing the attention on two different drapery types. Similarly, the procedure can be implemented on other installation types, keeping fixed the identification of the main components and the effects of damage on the overall behaviour. A site campaign was performed to validate the weights assigned to each issue, despite the valuable range of observed different solutions, indeed, a good agreement between the observed conditions of the system and the obtained results emerges. The double information obtained by the global score and the global maintenance level provided a compelling solution to understand both the severity and the extension of the possible required maintenance intervention. Further developments can be achieved, expanding the methodology for other mitigation measures [27].

\section{ACKNOWLEDGEMENTS}

his work has been supported by Regione Autonoma Valle d'Aosta under the framework of RED - Risk Evaluation Dashboard project. 


\section{REFERENCES}

[1] Ferraiolo, F. (2005). I rivestimenti superficiali. GEAM Geoingegneria Ambientale e Mineraria, XLII, pp. 45-53.

[2] Giani, G. (1992). Rock slope stability analysis. Balkema, Rotterdam (NL).

[3] Volkwein, A., Schellenberg, K., Labiouse, V., Agliardi, F., Berger, F., Bourrier, F., Dorren, L., Gerber, W., and Jaboyedoff, M. (2011). Rockfall characterisation and structural protection - a review, Natural Hazards and Earth System Sciences, 11, pp. 2617-2651, DOI: 10.5194/nhess-11-2617-2011.

[4] Bertolo, P., Oggeri, C., and Peila, D. (2009). Full-scale testing of draped nets for rockfall protection, Canadian Geotechnical Journal, 46, pp. 306-316. DOI: 10.1139/T08-126.

[5] Shu, S., Muhunthan, B., Badger, T., and Grandorff, R. (2005). Load testing of anchors for wire mesh and cable net rockfall slope protection systems, Engineering Geology, 79, pp. 162-176. DOI: 10.1016/j.enggeo.2005.01.008.

[6] Peila, D., Pelizza, S., and Sassudelli, F. (1998). Evaluation of behaviour of rockfall restraining nets by full scale tests, Rock Mechanics and Rock Engineering, 31, pp. 1-24. DOI: 10.1007/s006030050.

[7] Blanco-Fernandez, E., Castro-Fresno, D., del Coz Diaz, J., and Lopez-Quijada, L. (2011). Flexible systems anchored to the ground for slope stabilisation: Critical review of existing design methods, Engineering Geology, 122, pp. $129-145$. DOI: 10.1016/j.enggeo.2011.05.014.

[8] Giacchetti, G. and Bertolo, P. (2010). Approccio al calcolo dei sistemi di reti con chiodi per il consolidamento delle pareti rocciose, GEAM Geoingegneria Ambientale e Mineraria, XLVII, pp. 33-42.

[9] Giacchetti, G. and Grimod, A. (2015). Rockfall mitigation using simple drapery system: Design approach. In Engineering Geology for Society and Territory, 2, pp. 1881-1884.

[10] Blanco-Fernandez, E., Castro-Fresno, D., del Coz Diaz, J., Navarro-Manso, A., and Alonso-Martinez, M. (2016). Flexible membranes anchored to the ground for slope stabilisation: Numerical modelling of soil slopes using SPH, Computer and Geotechnics, 78, pp. 1-10. DOI: 10.1016/j.compgeo.2016.04.014.

[11] Castro-Fresno, D., del Coz Diaz, J., López, L., and García Nieto, P. (2008). Evaluation of the resistant capacity of cable nets using the finite element method and experimental validation, Engineering Geology, 100, pp. 1-10.

DOI: 10.1016/j.enggeo.2008.02.007.

[12] Sasiharan, N., Muhunthan, B., Badger, T., Shu, S., and Carradine, D. (2006). Numerical analysis of the performance of wire mesh and cable net rockfall protection systems, Engineering Geology, 88, pp. 121-132.

DOI: $10.1016 /$ j.enggeo.2006.09.005.

[13] Thoeni, K., Giacomini, A., Lambert, C., and Sloan, S. (2013). Numerical investigation on the performance of a rockfall drapery system. In Bischoff, M., Onate, E., Owen, R., Ramm, E., and Wriggers, P., eds., III International Conference on Particle- based Methods - Fundamentals and Applications - PARTICLES 2013, pp. 1-10.

[14] Valfré, A. (2006). Dimensionamento di reti metalliche in aderenza per scarpate rocciose mediante modellazioni numeriche, GEAM Geoingegneria Ambientale e Mineraria, XLIII, pp. 47-53.

[15] Shu, S., Muhunthan, B., and Badger, T. (2005). Snow loads on wire mesh and cable net rockfall slope protection systems. Engineering Geology, 81, pp. 15-31. DOI: 10.1016/j.enggeo.2005.06.007.

[16] Gratchev, I., Kim, D., and Chung, M. (2015). Study of the interface friction between mesh and rock surface in drapery system for rock fall hazard control, Engineering Geology, 199, pp. 12-18. DOI: 10.1016/j.enggeo.2015.10.005.

[17] Chakravorty, M., Frangopol, D., Mosher, R., and Pytte, J. (1995). Time-dependent reliability of rock-anchored structures, Reliability Engineering and System Safety, 47, pp. 231-236.

[18] Jiang, S.-H., Li, D.-Q., Zhang, L.-M., and Zhou, C.-B. (2014). Time-dependent system reliability of anchored rock slopes considering rock bolt corrosion effect. Engineering Geology, 175, pp. 1-8. DOI: 10.1016/0951-8320(94)00068-Y.

[19] Xia, N., Liang, R., Payer, J., and Patnaik, A. (2013). Probabilistic modelling of the bond deterioration of fully-grouted rock bolts subject to spatiotemporally stochastic corrosion, Structure and Infrastructure Engineering, 9, pp. 1161-1176. DOI: 10.1080/15732479.2012.670649

[20] Muhunthan, B., Shu, S., Sasiharan, N., Hattamleh, O., Badger, T., Lowell, S., and Duffy, J. (2005). Analysis and design of wire/mesh cable net slope protection. Technical report, Washington State Transportation Commission - Department of Transportation, U.S. Department of Transportation - Federal Highway Administration.

[21] Giacomini, A., Thoeni, K., Lambert, C., Booth, S., and Sloan, S. (2012). Experimental study on rockfall drapery system for open pit highwalls, International Journal of Rock Mechanics \& Mining Sciences, 56, pp. 171-181.

DOI: $10.1016 /$ j.ijrmms.2012.07.030

[22] Ente Italiano di Unificazione (2012). UNI 11437:2012 Rockfall Protective Measures - Tests On Meshes For Slopes Coverage. UNI. 
[23] ASTM (2016). ASTM A975:2016. Standard Specification for Double-Twisted Hexag- onal Mesh Gabions and Revet Mattresses (Metallic-Coated Steel Wire or Metallic-Coated Steel Wire With Poly (Vinyl Chloride) (PVC) Coating).

[24] Dodgson, J., Spackman, M., Pearman, A., and Phillips, L. (2009). Multi-criteria analysis: a manual. Technical report, Department for Communities and Local Government: London.

[25] Karsak, E. and Ahiska, S. (2005). Practical common weight multi-criteria decision-making approach with an improved discriminating power for technology selection, International Journal of Production Research, 43, pp. 1537-1554. DOI: $10.1080 / 13528160412331326478$

[26] Catrinu, M. and Nordgård, D. (2010). Incorporating risk analysis and multi-criteria decision making in electricity distribution system asset management. In Briš, R., Guedes Soares, C., and Martorell, S., Eds., Reliability, Risk and Safety: Theory and Applications, 1, pp. 393-400.

[27] Marchelli, M. and De Biagi, V. (2018). Dynamic effects induced by the impact of debris flows on protection barriers, International Journal of Protective Structures, pp. 1-16. DOI: 10.1177/2041419618798378. 